\title{
Rendimentos de cortes, proporção tecidual da carcaça e composição centesimal da carne de caprinos jovens em função do grupo racial e do peso corporal de abate
}

\author{
[Cut yields, carcass and tissue composition proportion in meat from young goats \\ depending on the breed and slaughter body weight] \\ R.O. Marques ${ }^{1}$, J.J.L. Menezes ${ }^{1}$, H.C. Gonçalves ${ }^{1 *}$, B.B.L. Medeiros ${ }^{1}$, L. Rodrigues ${ }^{1}$, \\ G.I.L. Canizares ${ }^{1}$, H.F.B. Gomes ${ }^{2}$, R.O. Roça ${ }^{1}$ \\ ${ }^{1}$ Faculdade de Medicina Veterinária e Zootecnia (FMVZ) - Universidade Estadual Paulista (Unesp) - Botucatu, SP \\ ${ }^{2}$ Instituto de Ciências Agrárias e Ambientais - Universidade Federal do Mato Grosso - Sinop, MT

\section{RESUMO} \\ O objetivo do presente trabalho foi avaliar as proporções de cortes comerciais, tecidos do lombo e \\ composição da carne de cabritos de cinco grupos raciais: Alpino, 1/2 Boer + 1/2 Alpino (1/2 BA), 1/2 Anglo \\ Nubiano + 1/2 Alpino (1/2 ANA), 3/4 Boer + 1/4 Alpino (3/4 BA), 1/4 Boer + 1/4 Alpino + 1/2 Anglo Nubiano \\ (Tricross), submetidos a três pesos de abate $(25,30$ e $35 \mathrm{~kg}$ ) em sistema de confinamento, com utilização \\ de dieta completa. O cruzamento das raças Boer e Anglo Nubiana com fêmeas Alpinas apenas melhorou, \\ nos cabritos, os rendimentos de cortes considerados de terceira categoria, como pescoço e costela. Pesos \\ corporais de abate entre 30 e $35 \mathrm{~kg}$ devem ser preferidos por aumentarem a proporção de lombo, \\ reduzirem a proporção de pescoço nos Alpinos e aumentarem a de perna em Alpinos e 3/4 Boer, além de \\ proporcionarem quantidades adequadas de músculo e gordura intermuscular.
}

Palavras-chave: cabrito, cortes comerciais, músculo, osso

\begin{abstract}
The purpose of this study was to evaluate the commercial cuts, loin tissues and composition proportions in meant from five racial groups: Alpine, 1/2 Boer + 1/2 Alpine (1/2 BA), 1/2 Anglo Nubian + 1/2 Alpine (1/2 ANA), 3/4 Boer + 1/4 Alpine (3/4 BA), 1/4 Boer + 1/4 Alpine + 1/2 Anglo Nubian (Tricross), submitted to three slaughter weights $(25,30$ and $35 \mathrm{~kg})$ in feedlot, using a complete diet. The crossing of Boer and Anglo Nubian with Alpine females only improved, in kids, the yield of cuts considered third category such as neck and rib. Slaughter body weights between 30 and $35 \mathrm{~kg}$ should be preferred due to increase in the proportion of the loin, reduction in the proportion of the neck in Alpine and increase in the leg in Alpine and $3 / 4$ Boer, beyond the appropriate amounts of intermuscular fat and muscle.
\end{abstract}

Keywords: bone, commercial cuts, kid, muscle

\section{INTRODUÇÃO}

Como a intensificação da produção de carne de caprinos na região Sudeste está baseada em acasalamentos de matrizes de raças leiteiras com bodes de raças de corte ou mistas, torna-se imprescindível avaliar o efeito do mestiçamento, bem como determinar um peso de abate que ocasione aumento na proporção dos cortes nobres da carcaça, nas composições tecidual dos cortes e centesimal da carne adequadas.

Recebido em 23 de março de 2012

Aceito em 7 de maio de 2013

*Autor para correspondência (corresponding author)

E-mail: heraldo@fmvz.unesp.br
Geralmente a carcaça de pequenos ruminantes é comercializada por cortes, sendo os mais tradicionais denominados de: perna, lombo, paleta, costelas e pescoço, conforme descrito por Pereira Filho (2008).

O valor e a qualidade da carcaça e dos cortes são diretamente influenciados pela relação entre seu peso e composição (Sainz, 1996). Carcaças de boa qualidade devem apresentar elevada proporção de músculos, baixa proporção de ossos e quantidade adequada de gordura 
intermuscular, capaz de garantir a suculência e a maciez da carne, assim como boa quantidade de gordura subcutânea, que impeça uma perda excessiva de umidade durante o processo de resfriamento.

A espécie caprina apresenta carcaças magras com escassa gordura de cobertura (Morand-Fehr, 1985). Grande parte da gordura corporal dos caprinos, em torno de 50 a $60 \%$, acha-se depositada na cavidade abdominal, sendo a gordura subcutânea extremamente delgada quando comparada à dos ovinos. Observa-se que o aumento da maturidade dos animais leva a um aumento da proporção de gordura (Simela et al., 1999).

Em termos gerais, o padrão de desenvolvimento dos componentes da carcaça segue a seguinte ordem cronológica: ossos, músculo e, por último, gordura (Hashimoto, 2005); dessa forma, a determinação do peso de abate se reveste de grande importância.

A água é a substância mais abundante nos seres vivos, estando em torno de 70 a $80 \%$ no músculo. Por ser tão abundante, influencia atributos de qualidade da carne, tais como suculência, maciez, cor e sabor. A quantidade de água pode variar de músculo para músculo entre animais de mesma espécie e do mesmo músculo entre animais de espécies diferentes, mas geralmente a variação é pequena. Os teores de umidade para cabritos e cordeiros variaram de
74,12 a 75,04\%, respectivamente (Babiker et al., 1990).

A carne de caprinos jovens é caracterizada por baixo conteúdo de gordura intramuscular e subcutânea (Sheridan et al., 2003), o que, atualmente, está de acordo com os interesses dos consumidores, que valorizam o baixo teor de gordura dos alimentos.

A matéria mineral tem a função de manter a pressão osmótica das células. Está associada à água e à proteína; portanto, é encontrada em maior quantidade em músculos magros, em percentual de 1\% (Bonagurio, 2001).

Este trabalho teve o objetivo de avaliar o efeito do grupo racial e do peso de abate na proporção dos cortes cárneos, nas proporções tecidual da carcaça e centesimal da carne de caprinos jovens criados em confinamento.

\section{MATERIAL E MÉTODOS}

O experimento foi conduzido na Unesp Faculdade de Medicina Veterinária e Zootecnia, Campus de Botucatu, com aprovação do cômite de ética local, sob protocolo $\mathrm{n}^{\mathbf{o}} 104 / 2005$ CEEA.

Foram utilizados 74 cabritos, machos e fêmeas, pertencentes a cinco grupos raciais e abatidos quando atingiram os pesos de 25,30 e $35 \mathrm{~kg}$ (Tab. 1).

Tabela 1. Distribuição dos animais experimentais de acordo com o grupo racial e o peso corporal de abate

\begin{tabular}{|c|c|c|c|c|}
\hline \multirow{2}{*}{ Grupo racial (GR) } & \multicolumn{3}{|c|}{ Peso corporal de abate (PA) } & \multirow[b]{2}{*}{ Total } \\
\hline & $25 \mathrm{~kg}$ & $30 \mathrm{~kg}$ & $35 \mathrm{~kg}$ & \\
\hline Alpino (A) & 4 & 3 & 4 & 11 \\
\hline $1 / 2$ Boer $+1 / 2$ Alpino $(1 / 2$ BA $)$ & 5 & 4 & 4 & 13 \\
\hline $1 / 2$ Anglo Nubiano + $1 / 2$ Alpino ( $1 / 2$ ANA) & 3 & 3 & 4 & 10 \\
\hline $3 / 4$ Boer $+1 / 4$ Alpino $(3 / 4 \mathrm{BA})$ & 9 & 6 & 8 & 23 \\
\hline $1 / 4$ Boer + 1/4 Alpino + 1/2 Anglo Nubiano (TC) & 6 & 5 & 6 & 17 \\
\hline Totais & 27 & 21 & 26 & 74 \\
\hline
\end{tabular}

Após o nascimento, os cabritos foram separados das mães, tiveram o cordão umbilical tratado com solução iodada, foram pesados, identificados e receberam colostro pasteurizado durante três dias, duas vezes ao dia, em mamadeira individual. Após o fornecimento de colostro, o aleitamento artificial passou a ser coletivo, feito em baldes providos de bicos, utilizando-se leite de cabra fervido, fornecido em duas refeições diárias, até o $10^{\circ}$ dia, e, a partir do $11^{\circ}$ dia, um aleitamento por dia de manhã. A quantidade de leite oferecida diariamente não ultrapassou $1,5 \mathrm{~L}$, e o desmame foi realizado aos 60 dias. A partir da segunda semana, os cabritos tiveram à disposição concentrado farelado à vontade, com a seguinte composição em $\mathrm{g} / \mathrm{kg}$ : 490 de milho, 380 de farelo de soja, 100 de 
farelo de algodão, 20 de calcário e 10 de sal mineral.

Quando os cabritos completaram 28 dias de vida $(6,17 \pm 1,01 \mathrm{~kg})$, entraram no experimento e foram alojados em 10 baias coletivas, de acordo com o grupo racial (GR). Passaram, então, a receber dieta experimental contendo $70 \%$ de concentrado e $30 \%$ de feno de coast-cross moído, formulada de acordo com exigências do NRC (2006), para ganho de $150 \mathrm{~g} /$ dia. A análise da dieta utilizada foi realizada no Laboratório de Bromatologia da FMVZ-Unesp de Botucatu (Tab. 2).

Tabela 2. Composição bromatológica da dieta experimental $(\mathrm{g} / \mathrm{kg})$

\begin{tabular}{ccccccc}
\hline MS & PB & EE & CZ & NDT $^{\text {a }}$ & FDN & FDA \\
\hline 906,4 & 213,5 & 23,4 & 54,1 & 707,1 & 458,5 & 219,7
\end{tabular}

MS- matéria seca, PB- proteína bruta, EE- extrato etéreo, CZ- cinzas, NDT- nutrientes digestíveis totais, FDN- fibra em detergente neutro, FDA- fibra em detergente ácido, ${ }^{a}$ estimado.

Ao atingirem o peso predeterminado para o abate, foram submetidos a jejum de 24 horas de sólidos e, em seguida, pesados, para se determinar o peso corporal ao abate (PA), sendo abatidos em frigorífico comercial, obedecendo ao fluxo normal do estabelecimento.

Após evisceração, as carcaças foram pesadas, obtendo-se o peso da carcaça quente, refrigeradas a $4^{\circ} \mathrm{C}$ por um período de 24 horas, obtendo-se, em seguida, o peso da carcaça fria.

Após o resfriamento, a carcaça foi dividida ao meio. Essa meia carcaça foi seccionada em cinco regiões anatômicas, o que gerou os seguintes cortes cárneos (Fig. 1): pescoço (PESC), paleta (PAL), costela (COST), lombo (L) e perna (P). Os cortes foram realizados conforme metodologia descrita em Yáñez (2002) e Pereira Filho (2003). Esses cortes foram feitos na metade esquerda da carcaça. O rendimento dos cortes foi obtido pela relação entre o peso do corte e o peso da meia carcaça.

Tendo em vista a elevada correlação entre os tecidos componentes da carcaça e do lombo (Fernandes, 1994), este foi selecionado como forma de representar a carcaça. A proporção de tecidos da carcaça foi feita por meio da dissecação do lombo, realizada no Laboratório de Análise de Carnes da Faculdade de Medicina Veterinária e Zootecnia-Unesp, Campus de Botucatu. O músculo Longissimus lumborum foi separado, pesado e congelado para determinação da composição centesimal.

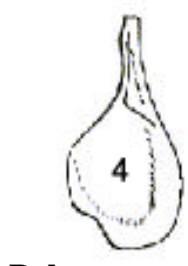

Paleta

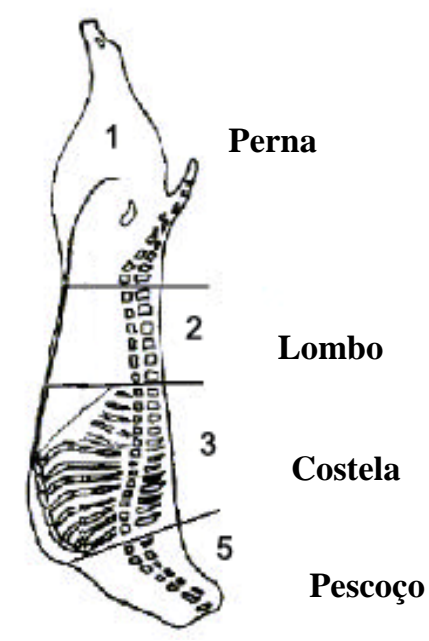

Figura 1. Cortes comerciais da 1/2 carcaça esquerda de caprinos. 1 - perna; 2 - lombo; 3 - costela; 4 paleta; 5 - pescoço (Yáñez, 2002; Pereira Filho, 2003). 
Foram determinadas as quantidades de tecido ósseo, muscular, adiposo (subdividido em gordura subcutânea e intermuscular) e gordura perirrenal (Delfa et al., 1989).

Para a avaliação da composição centesimal, o músculo Longissimus lumborum foi descongelado em refrigerador. A determinação da umidade foi realizada segundo o método 39.1.02 da A.O.A.C. (2007), para proteína, o método de Kjeldahl-micro, 39.1.19 da A.O.A.C. (2007), para determinação do nitrogênio total. A proteína bruta foi calculada em função dos teores de nitrogênio total, multiplicado pelo fator 6,25. $\mathrm{O}$ extrato etéreo e o resíduo mineral foram determinados segundo A.O.A.C. (2007), itens 39.1.05 e 39.1.09, respectivamente.

O experimento foi conduzido no delineamento em blocos ao acaso (sexo), e os dados submetidos à análise de variância em esquema fatorial com 5 grupos raciais (GR) x 3 pesos de abate (PA), conforme modelo abaixo, e foi aplicado o teste de Tukey $(\mathrm{P}<0,05)$ para comparação entre médias.

$Y_{i j k}=u+S_{i}+P A_{j}+G R_{k}+P A * G R_{i j}+e_{i j k}$ , em que:

$Y_{i j k}=$ característica observada no animal do grupo racial $\mathrm{k}$, abatido com peso $\mathrm{j}$ e pertencente ao sexo i; $u=$ constante inerente aos dados; $S_{k}=$ efeito do bloco (sexo) i, sendo $\mathrm{i}=1$ : macho e 2 : fêmea; $P A_{j}=$ efeito do peso de abate $\mathrm{j}$, sendo $\mathrm{j}$ $=1: 25,2: 30$ e $3: 35 \mathrm{~kg} ; G R_{k}=$ efeito do grupo racial $\mathrm{k}$, sendo $\mathrm{k}=1: \mathrm{A}, 2: 1 / 2 \mathrm{BA}, 3:=1 / 2$ ANA, 4: 3/4 BA e 5: TC; $P A * G R_{j k}=$ efeito da interação entre peso ao abate $\mathrm{j}$ e grupo racial $\mathrm{k}$ e $e_{i j k}=$ erro associado à observação $\mathrm{Y}_{\mathrm{ijk}} \sim \operatorname{NID}\left(0 ; \sigma_{\mathrm{e}}^{2}\right)$.

As análises estatísticas dos dados experimentais foram processadas por meio do programa computacional SAEG, versão 8.0 ( UFV, 2000).

\section{RESULTADOS E DISCUSSÃO}

Após jejum, os pesos corporais de abate (PA) dos animais foram 27,26; 31,58 e 36,63kg para os pesos preestabelecidos 25,30 e $35 \mathrm{~kg}$, respectivamente.

Os cabritos precisaram de 143, 164 e 190 dias, em média, para atingirem os pesos de 25,30 e $35 \mathrm{~kg}$, respectivamente, sendo que os Alpinos apresentaram média superior aos mestiços em todos os pesos corporais de abate (Tab. 3). O melhor desempenho dos mestiços possivelmente deve estar relacionado ao efeito da heterose.

Tabela 3. Médias de idade de cabritos para atingir os pesos corporais de abate de 25,30 e $35 \mathrm{~kg}$ de peso corporal em função do grupo racial

\begin{tabular}{|c|c|c|c|c|c|c|}
\hline \multirow[b]{2}{*}{ Média } & \multicolumn{5}{|c|}{ Grupo racial } & \multirow[b]{2}{*}{$\mathrm{CV}(\%)^{1}$} \\
\hline & $\mathrm{A}$ & $1 / 2 \mathrm{BA}$ & $1 / 2$ ANA & $3 / 4 \mathrm{BA}$ & TC & \\
\hline \multicolumn{7}{|c|}{ Idade para atingir $25 \mathrm{~kg}$ de peso corporal - I 25 (dias) } \\
\hline 143 & $170 \mathrm{a}$ & $133 \mathrm{bc}$ & $142 \mathrm{bc}$ & $146 b$ & $128 \mathrm{c}$ & 13,78 \\
\hline \multicolumn{7}{|c|}{ Idade para atingir $30 \mathrm{~kg}$ de peso corpora -I 30 (dias) } \\
\hline 164 & 199 a & $149 \mathrm{~b}$ & $161 \mathrm{~b}$ & $160 \mathrm{~b}$ & $152 \mathrm{~b}$ & 10,25 \\
\hline \multicolumn{7}{|c|}{ Idade para atingir $35 \mathrm{~kg}$ de peso corporal -I 35 (dias) } \\
\hline 190 & $233 \mathrm{a}$ & $172 \mathrm{~b}$ & $181 \mathrm{~b}$ & $181 \mathrm{~b}$ & $183 \mathrm{~b}$ & 10,15 \\
\hline
\end{tabular}

${ }^{1} \mathrm{CV}=$ coeficiente de variação. Médias seguidas de mesma letra nas linhas não diferem $(\mathrm{P}>0,05)$ pelo teste de Tukey. Grupo racial, 1/2 BA: 1/2 Boer + 1/2 Alpino, 1/2 ANA: 1/2 Anglo Nubiano + 1/2 Alpino, 3/4 BA: 3/4 Boer + 1/4 Alpino e TC:

$1 / 4$ Boer + 1/4 Alpino + 1/2 Anglo Nubiano.

A média dos rendimentos dos cortes comerciais (Tab. 4) foram semelhantes aos relatados por Hashimoto (2005), Silva et al. (2005) e Macedo et al. (2006), que trabalharam com mestiços Boer e raças de aptidão leiteira em condições semelhantes às deste estudo. 
Tabela 4. Médias dos rendimentos dos cortes cárneos da carcaça de cabritos em função do grupo racial e dos pesos corporais de abate $(\mathrm{kg} / 100 \mathrm{~kg})$

\begin{tabular}{|c|c|c|c|c|c|c|c|c|c|}
\hline \multirow{2}{*}{ Média } & \multicolumn{5}{|c|}{ Grupo racial } & \multicolumn{3}{|c|}{ Peso corporal de abate $(\mathrm{kg})$} & \multirow{2}{*}{$\begin{array}{l}C^{1} \\
(\%)\end{array}$} \\
\hline & A & $1 / 2 \mathrm{BA}$ & $1 / 2 \mathrm{ANA}$ & $3 / 4 \mathrm{BA}$ & $\mathrm{TC}$ & 25 & 30 & 35 & \\
\hline \multicolumn{10}{|c|}{ Rendimento da paleta (RPALETA) } \\
\hline 21,35 & 21,55 & 21,84 & 20,94 & 21,54 & 20,21 & 21,48 & 21,25 & 21,34 & 5,80 \\
\hline \multicolumn{10}{|c|}{ Rendimento do lombo (RLOMBO) } \\
\hline 12,71 & 12,45 & 12,97 & 12,66 & 13,07 & 12,41 & $12,34 b$ & $12,37 b$ & $13,44 \mathrm{a}$ & 8,83 \\
\hline \multicolumn{10}{|c|}{ Rendimento da costela (RCOST) } \\
\hline 27,29 & $27,04 \mathrm{ab}$ & $25,80 \mathrm{~b}$ & $28,27 \mathrm{a}$ & $27,78 \mathrm{a}$ & $27,57 \mathrm{ab}$ & 26,72 & 28,04 & 27,12 & 7,51 \\
\hline
\end{tabular}

${ }^{\mathrm{T}} \mathrm{CV}=$ coeficiente de variação. Médias seguidas de mesma letra nas linhas não diferem $(\mathrm{P}>0,05)$ pelo teste de Tukey. Grupo racial, 1/2 BA: 1/2 Boer + 1/2 Alpino, 1/2 ANA: 1/2 Anglo Nubiano + 1/2 Alpino, 3/4 BA: 3/4 Boer + 1/4 Alpino e TC:

$1 / 4$ Boer $+1 / 4$ Alpino + $1 / 2$ Anglo Nubiano.

Observou-se que os cortes considerados como de primeira (perna e lombo) representaram $42 \%$, de segunda (paleta) $21 \%$ e de terceira (pescoço e costela) $36 \%$ em relação ao total da carcaça fria. Esses rendimentos foram inferiores para os cortes de primeira e superiores para os de terceira, quando comparados a resultados reportados por Monte (2006), em caprinos SRD, mestiços $(1 / 2$ e $3 / 4)$ Boer x SRD e Anglo Nubiano x SRD, com valores de 55, 21 e $24 \%$ para cortes de primeira, segunda e terceira, respectivamente.

Dessa forma, os cortes de maior importância comercial mantêm grande participação na carcaça, representando quase $45 \%$ desta, considerando-se a perna e o lombo (cortes de primeira categoria), e atingindo mais de $60 \%$ com a incorporação da paleta, corte de segunda categoria, mas bastante valorizado pelo consumidor.
O rendimento dos cortes de terceira foi $36 \mathrm{~kg} / 100 \mathrm{~kg}$. É importante ressaltar que valores elevados para rendimentos de cortes considerados de terceira categoria, em qualquer circunstância, não são desejados, pois o valor comercial é inferior ao dos outros cortes.

O maior valor de rendimento de cortes da carcaça observado neste trabalho foi da perna. Isso é economicamente importante devido ao alto valor comercial, já que esse corte é considerado de primeira (Yamamoto et al., 2004).

A primeira geração de acasalamento da raça Boer com Alpina ( $\left.1 \frac{1}{2} \mathrm{BA}\right)$ apenas colaborou para aumentar o rendimento do corte pescoço no peso corporal de abate de $30 \mathrm{~kg}$ (Tab. 5), o que não traz nenhuma vantagem em termos econômicos, uma vez que o pescoço é um corte de terceira categoria. O Anglo Nubiano na primeira geração ( $1 \frac{2}{2}$ ANA) não alterou em nada o rendimento dos cortes em relação aos Alpinos (Tab. 4 e 5).

Tabela 5. Médias dos rendimentos dos cortes cárneos da carcaça de cabritos em função da interação grupo racial e pesos corporais de abate $(\mathrm{kg} / 100 \mathrm{~kg})$

\begin{tabular}{|c|c|c|c|c|c|c|c|}
\hline \multirow{2}{*}{ Média } & \multirow{2}{*}{$\begin{array}{c}\text { Peso corporal } \\
\text { de abate }\end{array}$} & \multicolumn{5}{|c|}{ Grupo racial } & \multirow{2}{*}{$\begin{array}{l}\mathrm{CV}^{\mathrm{T}} \\
(\%)\end{array}$} \\
\hline & & A & $1 / 2 \mathrm{BA}$ & $1 / 2$ ANA & $3 / 4 \mathrm{BA}$ & TC & \\
\hline \multicolumn{7}{|c|}{ Rendimento de pescoço (RPESC) } & \multirow{4}{*}{13,65} \\
\hline \multirow{4}{*}{8,95} & 25 & $9,54 \mathrm{aA}$ & $10,26 \mathrm{aA}$ & $8,76 \mathrm{aA}$ & $8,45 \mathrm{aA}$ & $8,74 \mathrm{aA}$ & \\
\hline & 30 & $6,19 b B$ & $9,25 \mathrm{aA}$ & $9,00 \mathrm{abA}$ & $8,52 \mathrm{abA}$ & $9,39 \mathrm{aA}$ & \\
\hline & 35 & $8,34 \mathrm{aAB}$ & $8,71 \mathrm{aA}$ & $8,90 \mathrm{aA}$ & $9,80 \mathrm{aA}$ & $9,90 \mathrm{aA}$ & \\
\hline & \multicolumn{6}{|c|}{ Rendimento da perna (RPERNA) } & \\
\hline \multirow{3}{*}{29,32} & 25 & $29,32 \mathrm{aB}$ & $29,91 \mathrm{aA}$ & $29,89 \mathrm{aA}$ & $29,62 \mathrm{aA}$ & $30,32 \mathrm{aA}$ & \multirow{3}{*}{4,63} \\
\hline & 30 & $32,33 \mathrm{aA}$ & $30,26 \mathrm{abA}$ & $29,00 \mathrm{abA}$ & $28,41 \mathrm{bAB}$ & $28,81 \mathrm{bA}$ & \\
\hline & 35 & $30,08 \mathrm{aAB}$ & $28,26 \mathrm{abA}$ & $28,37 \mathrm{abA}$ & $27,29 \mathrm{bB}$ & $29,77 \mathrm{aA}$ & \\
\hline
\end{tabular}

${ }^{1} \mathrm{CV}=$ coeficiente de variação. Médias seguidas de mesma letra, minúscula nas linhas e maiúscula nas colunas, não diferem $(\mathrm{P}>0,05)$ pelo teste de Tukey. Grupo racial, $1 / 2$ BA: $1 / 2$ Boer $+1 / 2$ Alpino, $1 / 2$ ANA: $1 / 2$ Anglo Nubiano $+1 / 2$ Alpino, 3/4 BA: 3/4 Boer + 1/4 Alpino e TC: 1/4 Boer + 1/4 Alpino + 1/2 Anglo Nubiano. 
Na segunda geração de cruzamento, tendo como base as fêmeas $1 / 2$ BA, o acasalamento com Boer $(3 / 4 \mathrm{BA})$ aumentou o rendimento de costela em relação aos 1/2 BA e não diferiu dos Alpinos (Tab. 4), diminuiu o rendimento da perna em relação aos Alpinos nos pesos corporais de abate de 30 e $35 \mathrm{~kg}$ (Tab. 5), porém não diferiu dos $1 / 2$ BA. Com o Anglo Nubiano (TC), o rendimento do pescoço foi aumentado em relação aos Alpinos, não diferiu dos $1 / 2 \mathrm{BA}$ no peso corporal de abate de $30 \mathrm{~kg}$ e reduziu o rendimento da perna em relação aos Alpinos no peso corporal de abate de $30 \mathrm{~kg}$ (Tab. 5).

O maior rendimento do lombo, independente do grupo racial, foi observado com o peso corporal de abate de $35 \mathrm{~kg}$. Para os Alpinos o peso de $30 \mathrm{~kg}$ reduziu o rendimento do pescoço, corte de terceira categoria, e aumentou o da perna, corte de primeira, em relação ao peso corporal de $25 \mathrm{~kg}$. Para os $3 / 4 \mathrm{BA}$ o peso de $35 \mathrm{~kg}$ reduziu o rendimento da perna em relação ao peso corporal de $25 \mathrm{~kg}$.

O maior rendimento de perna da raça Alpina pode estar relacionado ao maior comprimento desse corte em relação aos 3/4 BA. Mesmo com mestiços Boer apresentando melhor conformação e maior compacidade de perna, isso não foi suficiente para aumentar a proporção de perna, conforme observado por Menezes (2008) para essas características nas mesmas carcaças do presente trabalho e de Menezes et al. (2009) e Gomes et al. (2011).

A porcentagem de lombo foi influenciada pelo peso corporal de abate, sendo observado maior percentual no peso corporal de $35 \mathrm{~kg}$ e não havendo diferença nos pesos corporais de 25 e $30 \mathrm{~kg}$. Em estudos alométricos, o lombo é considerado como corte de desenvolvimento tardio em relação à meia carcaça e ao corpo do animal (Pereira Filho et al., 2008) por sua maior deposição de gordura (Galvani et al., 2008). Dessa forma, o peso corporal de $35 \mathrm{~kg}$ foi favorecido em relação aos demais.

Tendo em vista a proporção dos cortes cárneos, o peso corporal de abate mais indicado seria o de $35 \mathrm{~kg}$, pois este proporcionou maior porcentagem de cortes de primeira (lombo) e menor de terceira, no caso da costela dos $3 / 4 \mathrm{BA}$.

O tecido muscular apresentou maior rendimento entre os tecidos de importância econômica, com participação média de 56,52, seguido de 26,68 de tecido adiposo e $15,23 \mathrm{~kg} / 100 \mathrm{~kg}$ de osso (Tab. 6). Tais resultados diferem dos rendimentos de 71,$55 ; 16,20$ e $12,26 \mathrm{~kg} / 100 \mathrm{~kg}$ de músculo, gordura e osso, respectivamente, apresentados por Silva et al. (2005).

Outros tecidos que compõem a estrutura muscular (conectivo, artérias e veias) representaram $1,57 \mathrm{~kg} / 100 \mathrm{~kg}$ e, apesar de serem considerados como elementos que podem influenciar na qualidade e no rendimento do corte (Monte, 2006), não foram considerados neste trabalho.

Os mestiços não apresentaram diferença nos tecidos componentes da carcaça para os Alpinos. Nos cabritos de primeira geração de cruzamento, os mestiços Boer ( $1 / 2$ BA) apresentaram maior rendimento de gordura perirrenal que os $1 / 2$ ANA. Essa gordura é indesejável por estar localizada no interior da carcaça e, na maioria das vezes, é retirada junto com as vísceras nos abatedouros, reduzindo o rendimento da carcaça.

O maior rendimento de gordura total foi observado no peso corporal de abate de $35 \mathrm{~kg}$ em relação a $25 \mathrm{~kg}$, proporcionado pelo aumento do rendimento da gordura intermuscular, que apresentou o mesmo comportamento (Tab. 6). O rendimento do tecido muscular obedeceu à ordem inversa, sendo observado o menor valor no peso corporal de abate de $35 \mathrm{~kg}$, possivelmente devido ao aumento do teor de gordura total. Esse resultado é compreensível, tendo em vista que o crescimento do tecido muscular é considerado precoce e a gordura tardia (Galvani et al., 2008; Lourençon, 2011).

Com base na proporção dos tecidos do lombo, o peso corporal de abate entre 30 e $35 \mathrm{~kg}$ seria o mais indicado por apresentar quantidades satisfatórias de músculo e gordura intermuscular, uma vez que os outros componentes estudados não mostraram diferença entre os pesos corporais de abate avaliados. 
Tabela 6. Médias das proporções dos tecidos componentes do lombo de cabritos em função do grupo racial e dos pesos corporais de abate $(\mathrm{kg} / 100 \mathrm{~kg})$

\begin{tabular}{|c|c|c|c|c|c|c|c|c|c|}
\hline \multirow{2}{*}{ Média } & \multicolumn{5}{|c|}{ Grupo racial } & \multicolumn{3}{|c|}{ Peso corporal de abate $(\mathrm{kg})$} & \multirow{2}{*}{$\begin{array}{l}\mathrm{CV}^{1} \\
(\%)\end{array}$} \\
\hline & A & $1 / 2 \mathrm{BA}$ & $1 / 2$ ANA & $3 / 4 \mathrm{BA}$ & $\mathrm{TC}$ & 25 & 30 & 35 & \\
\hline \multicolumn{10}{|c|}{ Gordura total (GTOT) } \\
\hline 26,68 & 25,06 & 30,33 & 25,74 & 27,32 & 24,95 & $24,06 \mathrm{~b}$ & $27,23 \mathrm{ab}$ & $28,75 \mathrm{a}$ & 23,25 \\
\hline \multicolumn{10}{|c|}{ Gordura perirrenal (GREN) } \\
\hline 9,74 & $8,72 \mathrm{ab}$ & $13,91 \mathrm{a}$ & $6,21 \mathrm{~b}$ & $9,60 \mathrm{ab}$ & $10,27 \mathrm{ab}$ & 7,75 & 10,36 & 11,11 & 47,27 \\
\hline \multicolumn{10}{|c|}{ Gordura subcutânea (GSUB) } \\
\hline 10,72 & 10,15 & 10,21 & 12,98 & 11,17 & 9,08 & 10,92 & 10,41 & 10,83 & 39,31 \\
\hline \multicolumn{10}{|c|}{ Gordura intermuscular (GINTMUSC) } \\
\hline 6,22 & 6,19 & 6,20 & 6,54 & 6,55 & 5,59 & $5,39 b$ & $6,45 \mathrm{ab}$ & $6,81 \mathrm{a}$ & 28,53 \\
\hline \multicolumn{10}{|c|}{ Músculo (MUSC) } \\
\hline \multicolumn{10}{|c|}{ Osso (OSSO) } \\
\hline 15,23 & 17,20 & 14,09 & 14,73 & 14,32 & 15,83 & 15,71 & 15,07 & 14,93 & 26,00 \\
\hline
\end{tabular}

${ }^{\mathrm{T}} \mathrm{CV}=$ coeficiente de variação. Médias seguidas de mesma letra nas linhas não diferem $(\mathrm{P}>0,05)$ pelo teste de Tukey. Grupo racial, 1/2 BA: 1/2 Boer + 1/2 Alpino, 1/2 ANA: 1/2 Anglo Nubiano + 1/2 Alpino, 3/4 BA: 3/4 Boer + 1/4 Alpino e TC: $1 / 4$ Boer $+1 / 4$ Alpino $+1 / 2$ Anglo Nubiano.

As médias da composição centesimal do músculo Longissimus lumborum foi de $76,25 \%$ de umidade, $1,07 \%$ de cinzas, $21,04 \%$ de proteína e $2,30 \%$ de extrato etéreo (Tab. 7). Essas médias foram semelhantes a resultados obtidos por Rodrigues (2006), que obteve médias de 74,39\% de umidade, $1,02 \%$ de cinzas, $21,26 \%$ de proteína e $2,48 \%$ de extrato etéreo.

Tabela 7. Médias da composição centesimal do músculo Longissimus lumborum em função do grupo racial e do peso corporal de abate $(\mathrm{kg} / 100 \mathrm{~kg})$

\begin{tabular}{|c|c|c|c|c|c|c|c|c|c|}
\hline \multirow{2}{*}{ Média } & \multicolumn{5}{|c|}{ Grupo racial } & \multicolumn{3}{|c|}{ Peso corporal de abate $(\mathrm{kg})$} & \multirow{2}{*}{$\begin{array}{l}\mathrm{CV}^{\mathrm{I}} \\
(\%)\end{array}$} \\
\hline & $\mathrm{A}$ & $1 / 2 \mathrm{BA}$ & $1 / 2$ ANA & $3 / 4 \mathrm{BA}$ & $\mathrm{TC}$ & 25 & 30 & 35 & \\
\hline \multicolumn{10}{|c|}{ Umidade } \\
\hline 76,25 & $76,63 \mathrm{ab}$ & $76,00 \mathrm{ab}$ & $76,18 \mathrm{ab}$ & $75,60 \mathrm{~b}$ & $\begin{array}{l}76,82 \mathrm{a} \\
\text { zas }\end{array}$ & 76,69 & 75,90 & 76,15 & 1,70 \\
\hline 1,07 & 1,08 & 1,14 & 1,01 & $\begin{array}{l}1,03 \\
\text { Extr }\end{array}$ & $\begin{array}{l}1,07 \\
\text { etéreo }\end{array}$ & 1,06 & 1,07 & 1,08 & 11,37 \\
\hline 2,30 & $1,71 \mathrm{~b}$ & $1,96 \mathrm{~b}$ & $2,35 \mathrm{ab}$ & $3,30 \mathrm{a}$ & $2,19 b$ & 2,11 & 2,38 & 2,42 & 36,78 \\
\hline
\end{tabular}

${ }^{1} \mathrm{CV}=$ coeficiente de variação. Médias seguidas de mesma letra nas linhas não diferem $(\mathrm{P}>0,05)$ pelo teste de Tukey. Grupo racial, 1/2 BA: 1/2 Boer + 1/2 Alpino, 1/2 ANA: 1/2 Anglo Nubiano + 1/2 Alpino, 3/4 BA: 3/4 Boer + 1/4 Alpino e TC: $1 / 4$ Boer $+1 / 4$ Alpino $+1 / 2$ Anglo Nubiano.

$\mathrm{Na}$ primeira geração de cruzamento, as raças Boer (1/2 BA) e Anglo Nubiana (1/2 ANA) não alteraram a composição de umidade, cinza e extrato etéreo em relação aos Alpinos (Tab. 7). Apenas no peso corporal de abate de $25 \mathrm{~kg}$, os $1 / 2$ BA e $1 / 2$ ANA mostraram uma redução no teor de proteína em relação aos Alpinos (Tab. 8).

O único constituinte que teve sua composição alterada na segunda geração de cruzamento, em relação aos Alpinos, foi o extrato etéreo nos animais 3/4 BA (Tab. 7). Segundo Dhanda et al. (1999), essa é uma característica de animais de origem leiteira, os quais apresentam menor porcentagem de extrato etéreo na carne e desenvolvem maiores depósitos intracavitários de gordura.

O grupo racial Alpino apresentou maior porcentagem de proteína em relação aos demais grupos raciais no peso corporal de abate de $30 \mathrm{~kg}$ (Tab. 8), resultado que corrobora o de Bonagúrio (2001), sendo que animais mais tardios apresentam menos gordura, mais umidade $\mathrm{e}$ proteína do que os precoces. Essa afirmação está de acordo com o resultado desta pesquisa, pois o grupo racial Alpino levou mais tempo para atingir os pesos corporais de abate. 
Tabela 8. Médias da composição centesimal do músculo Longissimus lumborum em função da interação grupo racial e peso corporal de abate $(\mathrm{kg} / 100 \mathrm{~kg})$

\begin{tabular}{|c|c|c|c|c|c|c|c|}
\hline \multirow{2}{*}{ Média } & \multirow{2}{*}{$\begin{array}{c}\text { Peso corporal } \\
\text { de abate }\end{array}$} & \multicolumn{5}{|c|}{ Grupo racial } & \multirow{2}{*}{$\begin{array}{l}\mathrm{CV}^{1} \\
(\%)\end{array}$} \\
\hline & & A & $1 / 2 \mathrm{BA}$ & $1 / 2$ ANA & $3 / 4 \mathrm{BA}$ & TC & \\
\hline \multirow{3}{*}{21,04} & 25 & $20,97 \mathrm{aB}$ & $21,04 \mathrm{aA}$ & $\begin{array}{l}\text { Proteína } \\
19,80 \mathrm{aA}\end{array}$ & $20,32 \mathrm{aA}$ & $20,37 \mathrm{aA}$ & \multirow{3}{*}{6,80} \\
\hline & 30 & $26,29 \mathrm{aA}$ & $22,04 \mathrm{bA}$ & $20,23 \mathrm{bA}$ & $20,10 \mathrm{bA}$ & $20,54 \mathrm{bA}$ & \\
\hline & 35 & $22,44 \mathrm{aB}$ & $20,90 \mathrm{aA}$ & $20,31 \mathrm{aA}$ & $21,03 \mathrm{aA}$ & $20,74 \mathrm{aA}$ & \\
\hline
\end{tabular}

${ }^{1} \mathrm{CV}=$ coeficiente de variação. Médias seguidas de mesma letra, minúscula nas linhas e maiúscula nas colunas, não diferem $(\mathrm{P}>0,05)$ pelo teste de Tukey. Grupo racial, 1/2 BA: 1/2 Boer + 1/2 Alpino, 1/2 ANA: 1/2 Anglo Nubiano $+1 / 2$ Alpino, 3/4 BA: 3/4 Boer + 1/4 Alpino e TC: $1 / 4$ Boer + 1/4 Alpino + 1/2 Anglo Nubiano.

\section{CONCLUSÕES}

As raças Boer e Anglo Nubiana em cruzamento com Alpina produziram aumento no rendimento de cortes considerados de terceira categoria, como pescoço e costela, e aumentaram a proporção de extrato etéreo da carne na segunda geração de cruzamento com Boer. A adoção dessas raças em cruzamentos fica condicionada à remuneração regional desses cortes. Pesos corporais de abate entre 30 e $35 \mathrm{~kg}$ devem ser preferidos por aumentarem a proporção de lombo, considerado corte de primeira categoria, reduzirem a proporção de pescoço nos Alpinos, aumentarem a de perna em Alpinos e 3/4 Boer e proporcionarem adequadas quantidades de músculo e gordura intermuscular.

\section{REFERÊNCIAS}

ASSOCIATION Of Official Analytical Chemists - A.O.A.C. Official Methods of Analysis. 18.ed. Maryland, 2005, Current through Revision 2, 2007.

BABIKER, S.A.; EL KHIDER, I.A.; SHAFIE, S.A. Chemical composition and quality attributes of goat meat and lamb. Meat Science, v.28, p.273-277, 1990.

BONAGURIO, S. Qualidade da carne de cordeiros Santa Inês puros e mestiços com Texel abatidos com diferentes pesos. 2001. 149f. Dissertação (Mestrado em Zootecnia) Universidade Federal de Lavras, Lavras, 2001.

DELFA, R.; TEIXEIRA, A; COLOMERROCHER. A note on the use a lumbar joint as a predictor of body fat depots in aragonesa ewes with diferent body condition scores. Anim. Product., v.49, p.327-329, 1989.
DHANDA, J.S.; TAYLOR, D.G.;MCCOSKER, J.E.; MURRAY, PJ. The influence of goat genotype on the production of capretto and chevon carcass. 1- growth and carcass characteristics. Meat Sci., v.52, p.355-361. 1999.

FERNANDES, S. Peso vivo ao abate $e$ características da carcaça de cordeiros da raça Corriedale e mestiços Ilê de France $x$ Corriedale, recriados em confinamento. 1994. 81f. Dissertação (Mestrado em Zootecnia) Faculdade de Medicina Veterinária e Zootecnia, Universidade Estadual Paulista, Botucatu, 1994.

GALVANI, D.B. PIRES, C.C.; OLIVEIRA, F. et al. Crescimento alométrico dos componentes da carcaça de cordeiros Texel $\times$ Ile de France confinados do desmame aos $35 \mathrm{~kg}$ de peso vivo. Cienc. Rural, v.38, p.2574-2578, 2008.

GOMES, H.F.B.; MENEZES, J.J.L.; GONÇALVES, H.C. et al. Características da carcaça de carpinos de cinco grupos raciais criados em confinamento. Rev. Bras. Zootec., v.40, p.411-417, 2011.

HASHIMOTO, J.H. Desempenho, digestibilidade aparente e características de carcaça de cabritos Boer x Saanen confinados, recebendo rações com casca de soja em substituição ao milho. 2005. 87f. Dissertação (Mestrado em Zootecnia) - Universidade Estadual de Maringá, Maringá, SP.

LOURENÇON, R.V. Crescimento relativo dos cortes e tecidos da carcaça de caprinos de cinco grupos raciais terminados em pasto ou confinamento. 2011. 57f. Dissertação (Mestrado em Zootecnia) - Faculdade de Medicina Veterinária e Zootecnia, Universidade Estadual Paulista, Botucatu, SP. 
MACEDO, F.A.F.; REQUE, T.A.; GRANDE, P.A. Desempenho e proporção dos cortes de carcaças de cabritos mestiços Boer terminados com diferentes fontes de óleos. In: REUNIÃO ANUAL DA SOCIEDADE BRASILEIRA DE ZOOTECNIA, 43., 2006. João Pessoa. Anais... João Pessoa: Sociedade Brasileira de Zootecnia, 2006. 4f.

MENEZES, J.J.L. Desempenho e características de carcaça de cabritos de diferentes grupos raciais e pesos de abate. 2008. 93f. Tese (Doutorado em Zootecnia) - Faculdade de Medicina Veterinária e Zootecnia, Universidade Estadual Paulista, Botucatu, SP.

MENEZES, J.J.L.; GONÇALVES, H.C.; RIBEIRO, M.S. et al. Efeito do sexo, do grupo racial e da idade ao abate nas características de carcaça e maciez da carne de caprinos. Rev. Bras. Zootec., v.38, p.1769-1778, 2009.

MONTE, A.L.S. Composição regional e tecidual da carcaça, rendimento dos componentes não carcaça e qualidade da carne de cabritos mestiços Boer e Anglo-Nubiano e cabritos sem padrão racial definido. 2006. 181f. Tese (Doutorado em Zootecnia) - Universidade Federal do Ceará, Fortaleza, CE.

MORAND-FEHR, D.; BAS, P.; ROUZEAU, A.; HERVIEU, J. Development and characteristics of adipose deposits in males kids during growth from birth to weaning. Anim. Product., v.41, p.349-357, 1985.

NATIONAL Research Council - NRC. Nutrient requeriments of small ruminantes. Washington, D.C.: National Academy Press, 2001. 387p.

PEREIRA FILHO, J.M. Estudo do crescimento alométrico e das características de carcaça $e$ impacto econômico da restrição alimentar de cabritos F1 Boer x Saanen. 2003. 113f. Tese (Doutorado em Zootecnia) - Faculdade de Ciências Agrárias e Veterinárias, Universidade Estadual Paulista, Jaboticabal, 2003.

PEREIRA FILHO, J.M.; RESENDE, K.T.; TEIXEIRA, I.A.M.A. et al. Características da carcaça e alometria dos tecidos de cabritos F1 Boer x Saanen. Rev. Bras. Zootec., v.37, p.905912, 2008.
RODRIGUES, L. Somatotropina bovina recombinante $(r b S T)$ e grupo racial sobre o desempenho, características de carcaça $e$ qualidade da carne de caprinos em crescimento. 2006. 74f. Dissertação (Mestrado em Zootenia) Faculdade de Medicina Veterinária e Zootecnia, Universidade Estadual Paulista, Botucatu, SP.

SAINZ, R.D. Qualidade de carcaças e da carne bovina. In: REUNIÃO ANUAL DA SOCIEDADE BRASILEIRA DE ZOOTECNIA, 33., 1996, Fortaleza-CE. Anais... Fortaleza:SBZ, 1996. p.314.

SHERIDAN, R.; HOFFMAN, L.C.; FERREIRA, A.V. Meat quality of Boer goat kids and Mutton Merino lambs. 1. Commercial yields and chemical composition. J. Anim. Sci., v.76, p.6371, 2003.

SILVA, K.T. et al. Características quantitativas de carcaça, rendimentos de cortes e proporções e proporção dos tecidos de cabritos Boer x Saanen confinados, recebendo rações com diferentes níveis energéticos. In: REUNIÃO ANUAL DA SOCIEDADE BRASILEIRA DE ZOOTECNIA, 42., 2005, Goiânia. Anais... Goiânia: Sociedade Brasileira de Zootecnia, 2005. (1 CD-ROM).

SIMELA, L.; NDLOVU, R.L.; SIBANDA, L.M. Carcass characteristics of the marketed matebele goat from south-western. Small Ruminant Res., v.32, p.173-179, 1999.

UNIVERSIDADE FEDERAL DE VIÇOSA - UFV. Sistema de análises estatísticas e genéticas - SAEG. Versão 8.0. Viçosa, MG, 2000. 142p.

YAMAMOTO, S.M. MACEDO, F.A.F.; MEXIA, A.A. et al. Rendimento dos cortes e não componentes da carcaça de cordeiros terminados com dietas contendo diferentes fontes de óleo vegetal. Cienc. Rural, v.34, p.1909-1913, 2004

YAÑEZ, E.A. Desenvolvimento relativo dos tecidos e características da carcaça de cabritos Saanen, com diferentes pesos e níveis nutricionais. 2002. 85f. Tese (Doutorado em Zootecnia) - Faculdade de Ciências Agrárias e Veterinárias, Universidade Estadual Paulista, Jaboticabal. 2002. 